\title{
Determination of Synchronous Machine Parameters using iLab Shared Architecture
}

\author{
http://dx.doi.org/10.3991/ijoe.v10i3.3400 \\ Ahmed Naddami ${ }^{1}$, Ahmed Fahli ${ }^{1}$, Mourad Gourmaj ${ }^{1}$, Mohammed Moussetad ${ }^{2}$ \\ ${ }^{1}$ Université Hassan 1, Settat, Maroc \\ ${ }^{2}$ Université Hassan 2 Mohammedia, Casablanca, Maroc
}

\begin{abstract}
The target of this work is to describe experimental work via the internet within the different laboratories of Hassan $1^{\text {st }}$ University in Morocco. This also involves partners in the eSience group within the Tempus project framework. This paper focuses on implementation of the first remote laboratory in Hassan $1^{\text {st }}$ University in Morocco. The control system for this remote laboratory was implemented using National Instrument's LabVIEW and CompactRIO, LabVIEW FPGA and LabVIEW Real-Time technologies. The experiment determines the characteristics of synchronous machines. Students access our platform via the Internet to determine the parameters of Open Circuit characteristics (OCC), short circuit characteristics (SCC) and synchronous reactance Xs. These online experiments were deployed on the interactive version of iLab Shared architecture (ISA).
\end{abstract}

Index Terms-Remote laboratories, iLab, Synchronous motor, and LabVIEW.

\section{INTRODUCTION}

In engineering education, practical work is an important complement to theoretical courses. Students come to the laboratory to conduct experiments and appreciate the discrepancies between their observations and predictions according to the theoretical courses. However, due to several limiting factors in traditional laboratory experiments, students cannot get the necessary experiences.

In this paper, we focus on the online laboratory being used by the Polydisciplinary Faculty in Khouribga (PFK) Hassan $1^{\text {st }}$ University in Morocco. This laboratory, called OnlineLab, is a part of the eSience project (rESeau maghrébIn de laboratoirEs à distance) carried out in cooperation with Austria, France, Tunisia, Algeria, Romania, Greece and Morocco and is financed by Tempus. The Tempus project aims to create a series of remote laboratories in Morocco, Tunisia and Algeria in cooperation with France, Austria, Romania and Greece; it is financed by the European Union. OnlineLab, the first remote laboratory in Morocco, was implemented and developed to allow students to conduct practical work from anywhere at any time without being physically present. Furthermore, due to student numbers, security concerns, expensive fees and space required for electrical engineering equipment, the remote laboratory was the solution adopted by the PFK. Starting in September 2013, the PFK platform has been available at http://www.onlinelab-uhp.ma/ilab ServiceBroker.

Internet technologies and software applications (such as National Instrument's LabVIEW, which is considered as the leading professional software for analysis, data acquisition, real-time control and remote laboratories) have had an enormous impact on engineering education. Benefiting from that, the Khouribga OnlineLab research team has developed an innovative and flexible remote laboratory to determine the synchronous reactance for a synchronous machine in real-time via internet. The platform is controlled using National Instrument's CompactRIO (cRIO) based on the reconfigurable Filed-Programmable Gate Array (FPGA) technology and real-time processor [6].

There are many software applications used to share the online laboratory. In our case, we have chosen the iLab Shared Architecture (ISA) of Massachusetts Institute of Technology (MIT) that provides a platform independent framework for deployment [2].This architecture is divided into three distinct parts: Lab client, Service Broker middleware and Lab Server that facilitate easily deploying and sharing online laboratory around the world. In this way, the ISA not only eases deployment of remote laboratories but also makes them easier to share across institutions [8].

\section{DESCRIPTION}

\section{A. The iLab Shared Architecture (ISA)}

The ISA provides a common framework on which laboratory instrumentation can be integrated to create remote laboratories [3] that allow students to conduct and run laboratory equipment remotely through internet for a large number of users geographically dispersed throughout the world [4]. There are three different types of architecture available in the framework of online laboratories: Batched experiments, Sensor experiments and Interactive experiments.

In the first architecture (Figure1), the batched experiment, students need to specify and configure all of the specifications of the experiment before running it. Additionally, they do not need to stay and wait for the results; the results can be retrieved later.

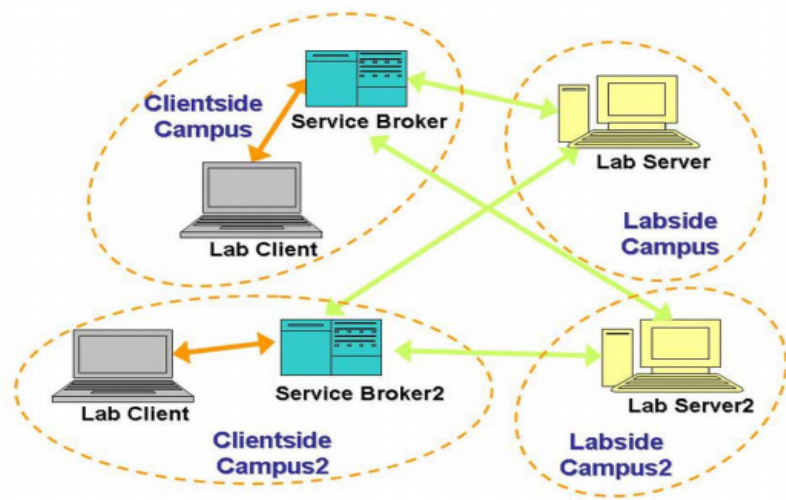

Figure 1. Batched iLab Architecture 
In the second architecture, the sensor experiment, students cannot specify or configure any of the parameters. They can monitor and control real-time data streams without influencing the phenomena being measured.

In the last architecture (Figure 2), the interactive experiment, students can dynamically modify one or more of the inputs to the experiment during its execution.

In our platform, students can dynamically change the motor speed, the current, the voltage, and the load. To accommodate this, we have adopted an interactive experiment that essentially contains three parts: the Interactive Lab Client Server, the Interactive Service Broker as a middleware and the Interactive Lab Server.

The Interactive Lab Client Server is the user interface that allows students to access and interact dynamically with the lab [1].

The Interactive Lab Server communicates with the Interactive Service Broker via the web-services; it is responsible for processing experiment execution requests. This tier is connected directly with the laboratory equipment [4] - [1].

The Interactive Service Broker is the heart of the ISA. This tier provides the shared common services, generic administration, scheduling, authentication, authorization, data storage and launching labs. The Service Broker also determines what features of the laboratory each user has access to during his log-on session [9].

In addition to the three parts of the interactive architecture, there are three new tiers:

The Experiment Storage (ESS) is a stand-alone web service that allows Service Brokers, lab servers and lab clients to store experiment data. It also provides storage of binary data (images, video or audio) and XML associated with experiments. In order to support interactive experiments that require scheduled access, the iLab interactive architecture envisions scheduling servers and services that enable students from different campuses to reserve time periods to execute experiments. Since the User-side and Lab-side require different functionalities. Scheduling Services in the ISA consists of two separate, web servicesbased systems: the User-side Scheduling Service (USS) and the Lab-side Scheduling Service (LSS).

The Lab-side Scheduling Service is responsible for defining the scheduling policy for a particular lab. The LSS is designed to run in conjunction with multiple USSs and may schedule multiple lab servers. A lab administrator can set lab specific policy from the LSS.

The User-side Scheduling is responsible for notifying students if their reservation must be canceled and for considering course/lab requirements when distributing time blocks.

\section{B. Hassan $1^{\text {st Laboratory }}$}

\section{1) Software Part}

As described before, our laboratory is based on Interactive Shared Architecture to deploy and share the labs (Figure 3). The platform is available on http://www.onlinelab-uhp.ma/servicebroker/ (Figure 4). The students browse the service broker domiciled at the previously referenced URL to register and request membership to the group associated with the laboratory. To do this, students must access the service broker, login page and ask to supply for their user names and passwords. This procedure allows permission and access to the booking system, and then they choose the available lab experiment to launch it.

\section{2) Hardware part}

Several years ago, controlling and studying real-time operations of electrical machines was a very challenging problem. But with the rapid evolution of hardware and embedded systems, especially the FPGA, designers are now able to create, test, make modifications and greatly reduce development time [5].

The hardware part of our OnlineLab (Figure 5) contains a variable-frequency drive, an excitation, an asynchronous machine, a synchronous motor, loads, and a webcam.

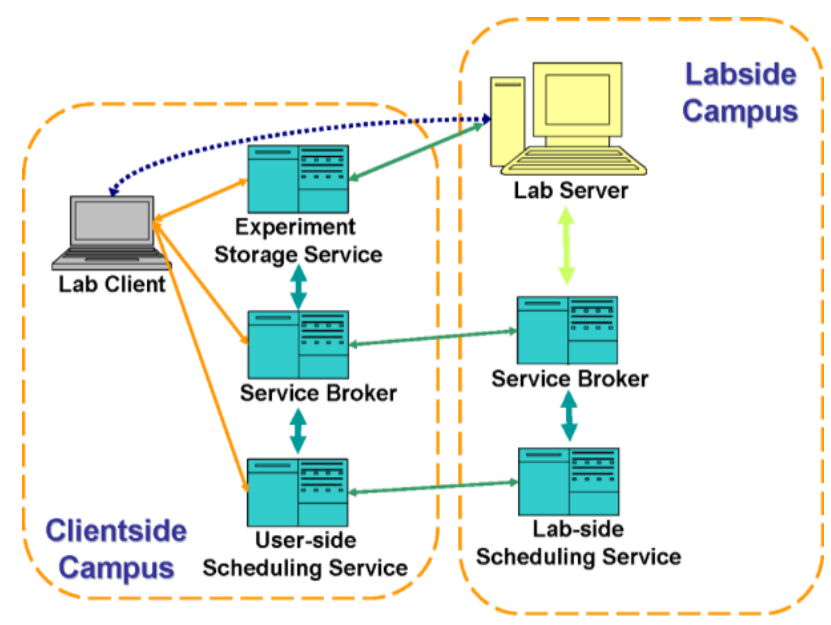

Figure 2. Interactive iLab Architecture

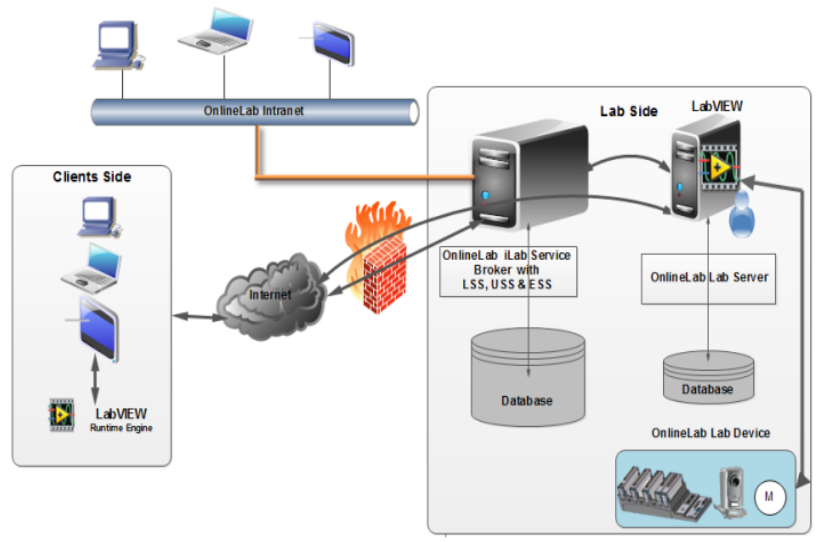

Figure 3. The architecture of the ISA OnlineLab laboratory

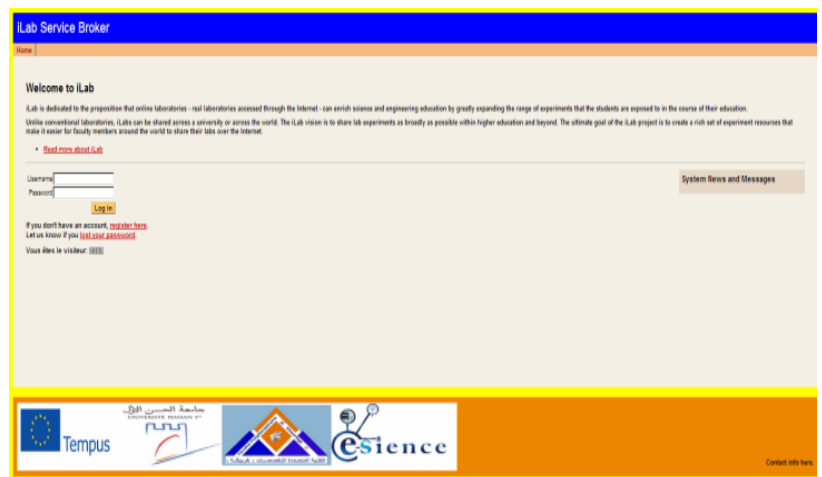

Figure 4. The architecture of the ISA OnlineLab laboratory 
To control this equipment (Figure 6), we are using cRIO, made by National Instruments, for real-time control and data acquisition powered by reconfigurable I/O (RIO) FPGA technology for ultrahigh performance and customization. NI cRIO incorporates a real-time processor and reconfigurable FPGA for reliable stand-alone embedded or distributed applications and hot-swappable industrial I/O modules with built-in signal conditioning for direct connection to sensors and actuators. cRIO represents a lowcost architecture with open access to low-level hardware resources. cRIO embedded systems are developed using high-productivity LabVIEW graphical programming tools for rapid development [6].

The cRIO, contains three parts [7]:

Real-Time Controller: The real-time controller consists of an industry PC that reliably and deterministically executes LabVIEW real-time applications and offers multirate control, execution tracing, onboard data logging, and communication with peripherals [7]. It receives the data from the FPGA, executes the control algorithms, and sends the data to the FPGA in real-time.

Reconfigurable FPGA Chassis: The reconfigurable FPGA chassis is the center of the embedded system architecture. The reconfigurable I/O (RIO) FPGA is directly connected to the $\mathrm{I} / \mathrm{O}$ modules for high-performance access to the $\mathrm{I} / \mathrm{O}$ circuitry of each module and unlimited timing, triggering, and synchronization flexibility; in addition, it is responsible for transferring data to the real-time controller to execute real-time analysis [6] and to govern the operation on the synchronous machine.

Industrial I/O Modules (RIO): RIOis a flexible unit in which one can insert different I/O-modules that can be mapped in the VI; also the I/O modules contain built-in signal conditioning and isolation, such as Digital input/output, Alternator controlled by NI cRIO, and Run Variable-frequency drive controlled by NI cRIO [7]. Each $\mathrm{I} / \mathrm{O}$ module is directly connected to the FPGA, providing low-level customization of timing and I/O signal processing [10].

The LabVIEW software and the entire modules are installed in the Host Computer (OnlineLab Lab Server) that controls the whole system. The host computer communicates synchronously with the chassis over a TCP/IP connection, a real-time controller implements the major complicated algorithms, and the FPGA module processes input output data [6].

The implementation of this remote laboratory is divided into two parts: writing the code in FPGA mode and controlling it through the Host. The control and protection methods are implemented using the LabVIEW RT and FPGA modules on a Host computer. The code is downloaded to the cRIO controller and the FPGA for execution; then LabVIEW compiles and implements the code in the hardware part [7, 11] (Figure 7).

\section{THE EXPERIMENT: A SYNCHRONOUS REACTANCE}

In this work, the main objective was to build an interactive system to determine the synchronous reactance at any time with any browser in real-time using a client interface implemented using National Instrument's LabVIEW and deployed as an interactive lab in the ISA (Figure 8). For this, the student must download and install the LabVIEW plug-in for the browser available at http://www.ni.com/. The synchronous reactance experiment installation has

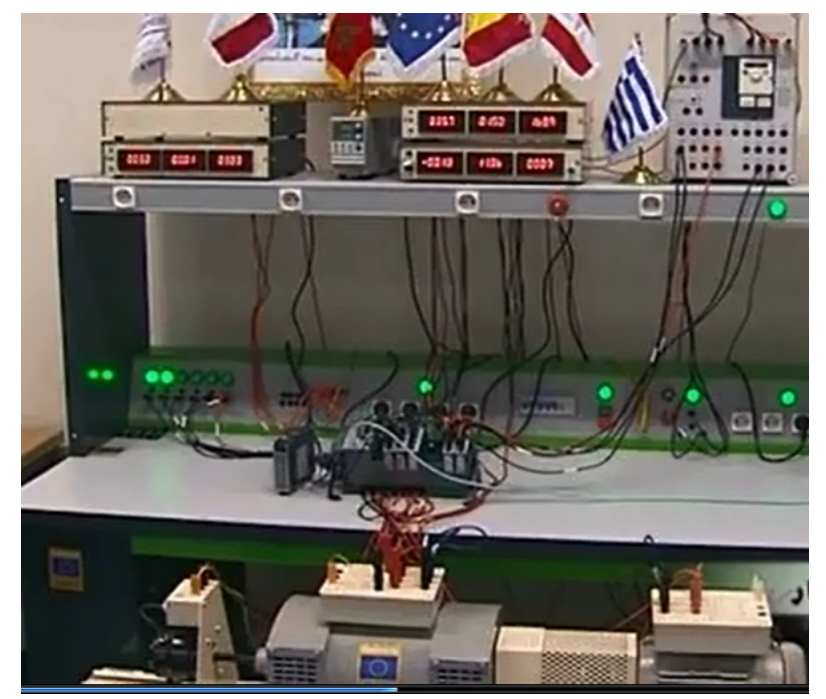

Figure 5. OnlineLab platform

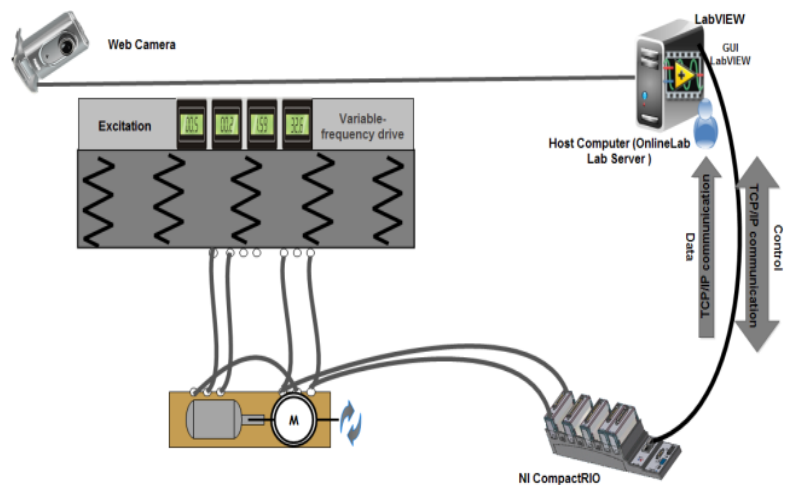

Figure 6. The Architecture of the OnlineLab laboratory

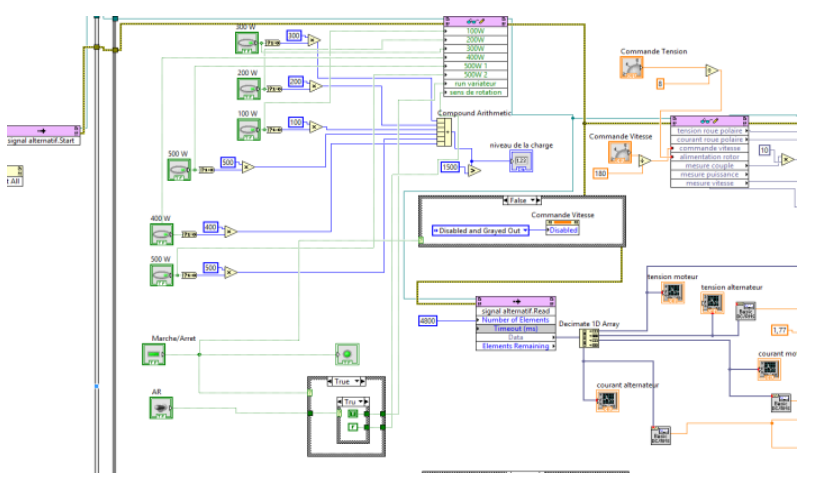

Figure 7. Block Diagram of FPGA VI

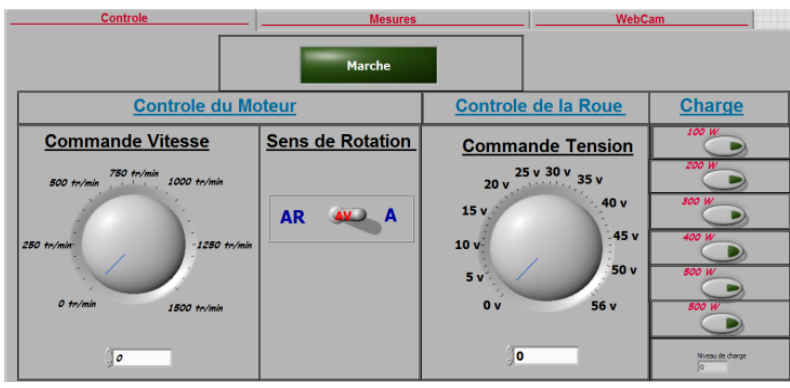

Figure 8. LabVIEW client interface

real-time webcam streaming. Students see the live scenes of the experiment and are working and controlling a real running motor. They can learn the real values of current 
and voltage being measured through digital displays installed in the test bed based on the synchronous machine.

Synchronous machines are $\mathrm{AC}$ machines that have a field circuit supplied by an external DC source; it is reversible. It can operate as a motor or generator (alternator), but the most common application of the synchronous machine in the power industry is as a three-phase generator.

In a synchronous generator, a DC current is applied to the rotor winding, producing a rotor magnetic field. The rotor is then turned by external means, producing a rotating magnetic field, which induces a 3-phase voltage within the stator winding.

In a synchronous motor, a 3-phase set of stator currents produces a rotating magnetic field, causing the rotor magnetic field to align with it. The rotor magnetic field is produced by a DC current applied to the rotor winding.

The components of the synchronous reactance can be determined by performing two tests on the synchronous machine: one made with the armature terminals opencircuited and the second with the armature terminals shortcircuited.

\section{A. Open circuit characteristics (OCC)}

With the stator windings open-circuited, the synchronous machine is driven at synchronous speed, while the field current If is varied. The open-circuit voltage $V I$ across the stator windings is measured. This test provides data for a plot of $V I$ (open load line) vs. If (excitation current). This plot is known as the open-circuit characteristic (OCC) and represents the variation of the generator voltage with respect to the field current (Figure 9).

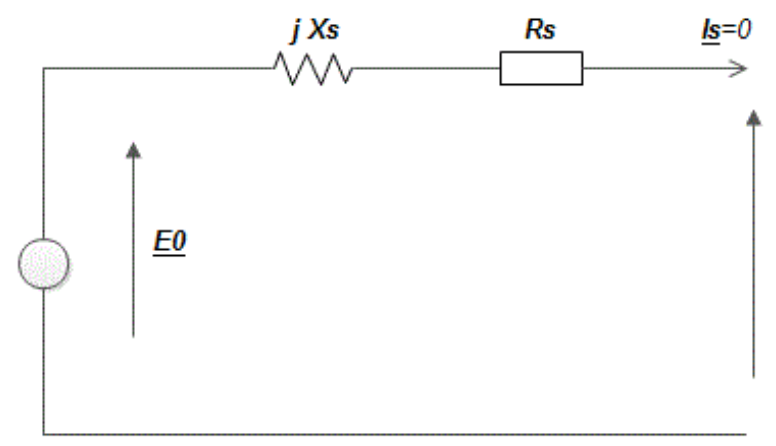

$\underline{V s}$

Figure 9. Circuit diagram to performopen-circuit characteristic (OCC)

The open circuit test steps:

- The generator is turned at the rated speed

- The terminals are disconnected from all loads, and the field current is set to zero.

- The field current is gradually increased in steps, and the terminal voltage is measured at each step along the way.

- It is thus possible to obtain an open-circuit characteristic of a generator ( $E 0$ or $V 1$ versus $I f$ ) from this information

With the machine being driven at nominal speed, the open load line voltage as a function of excitation current is measured.

\section{B. Short circuit characteristics (SCC)}

With the stator input terminals short-circuited (the stator windings connected in parallel), the synchronous machine is driven at synchronous speed while the field current If is varied. The current $I s$ in each of the three stator windings is measured, and an average value is determined. This test provides data for a plot of $I s$ vs. If. This plot is known as the short-circuit characteristic (SCC) and represents the variation of the armature (stator) current with respect to the field current (Figure 10).

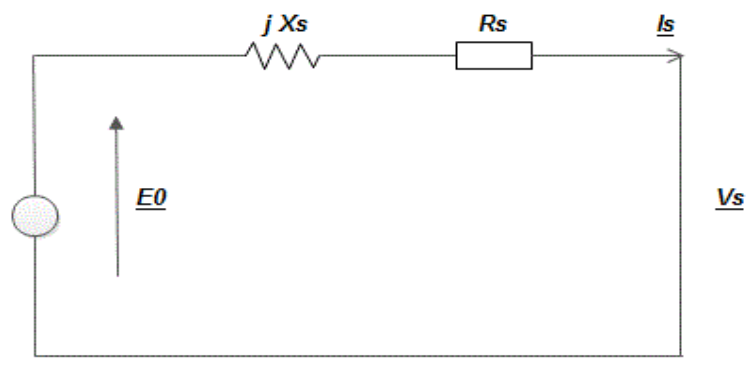

Figure 10. Circuit diagram to perform short circuit characteristic (SCC)

The short circuit test steps:

- Adjust the field current to zero and short circuit the terminals of the generator through a set of ammeters.

- Record the armature current $I_{s c}$ as the field current is increased.

- Such a plot is called short-circuit characteristic.

With the machine being driven at the nominal speed and the armature being short-circuit (OCC), the line current as a function of the excitation current (SCC) is measured (Figure 12).

\section{Determination of the reactance $X s$}

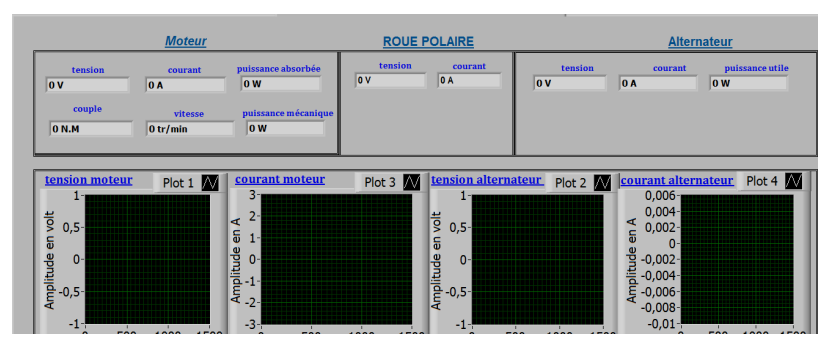

Figure 11. LabVIEW client interface

When the terminals are short circuited, the armature current is(Figure 11):

$$
I_{A}=\frac{E_{0}}{R s+j X s}
$$

and its magnitude is:

$$
I_{A}=\frac{E_{0}}{\sqrt{R^{2} S+X^{2} S}}
$$

From both tests, we can find the internal machine impedance $\left(E_{0}\right.$ from OCC, $I_{A}$ from SCC):

$$
Z s=\sqrt{R^{2} S+X^{2} S}=\frac{E_{0}}{I_{A}}
$$

Since $X s>>R s$, the equation reduces to:

$$
X s \approx \frac{E_{0}}{I_{A}}
$$


PAPER

Determination of Synchronous Machine Parameters using iLab Shared Architecture

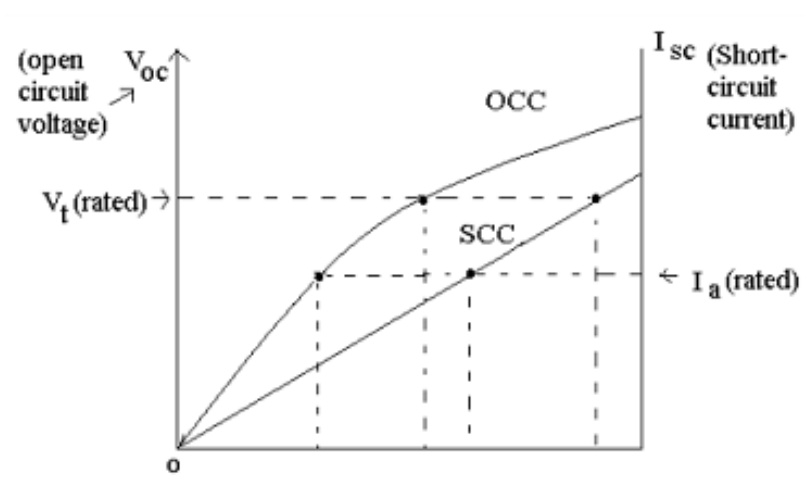

Figure 12. OCC \& SCC characteristics

\section{EVALUATION}

Since September 2013, more than 200 students have been using OnlineLab to handle and measure the machine laboratory; the students have provided interesting feedback and have been overwhelmingly positive. This online experiment supports curricula of Electrical Engineering \&Industrial Informatics, Physic Sciences, Industrial Engineering, and Automatic \& Telecommunication programs (Figures 13and14).

\section{A. Student Questionnaire:}

Before using Khouribga OnlineLab:

1. You understand remote laboratories?

2. You can operate an electrical machine in a physical laboratory that reaches $380 \mathrm{~V}$ without teacher supervision?

3. How many students per experimental test bed were in the electrical machines laboratory?

4. In the electrical machines laboratory, time was sufficient to do all of the tests and measuring parameters?

\section{After using Khouribga OnlineLab:}

1. In your opinion, remote labs can replace real labs?

2. Client interfaces are easy to use?

3. You can operate an electrical machine that reaches $380 \mathrm{~V}$ without teacher supervision?

4. This lab should be used next year?

5. Via the Khouribga OnlineLab, time is sufficient to do all the tests and measuring parameters?

\section{CONCLUSION}

This work has presented the realization of a remote laboratory deployed and shared using an ISA. It is dedicated to students of the eSience group to allow them to conduct and control real-time synchronous machines from anywhere and at any time. The system has been implemented and controlled by combining National Instrument's LabVIEW and cRIO to run the entire platform.

\section{ACKNOWLEDGEMENT}

This project has been funded with support from the European Commission. This publication reflects the views only of the author, and the Commission cannot be held responsible for any use that may be made of the information contained therein.
TABLE I.

STUDENTS RESPONSES

\begin{tabular}{|c|c|c|c|c|c|c|c|c|c|}
\hline Question & $\mathbf{1}$ & $\mathbf{2}$ & $\mathbf{3}$ & $\mathbf{4}$ & $\mathbf{1}$ & $\mathbf{2}$ & $\mathbf{3}$ & $\mathbf{4}$ & $\mathbf{5}$ \\
\hline YES(\%) & 5 & 2 & $\begin{array}{c}\text { More } \\
\text { than } 6\end{array}$ & 10 & 65 & 93 & 100 & 100 & 97 \\
\cline { 1 - 9 } NO(\%) & 95 & 98 & & 90 & 35 & 7 & 0 & 0 & 3 \\
\hline
\end{tabular}

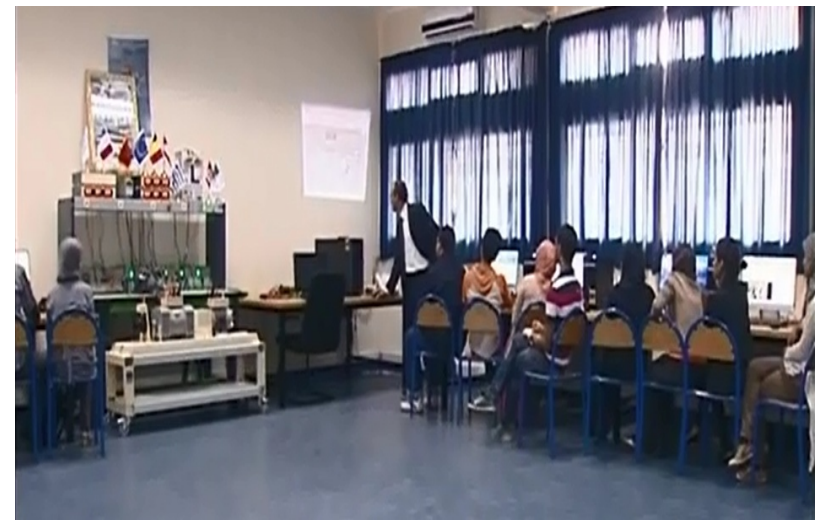

Figure 13. Students in Khouribga OnlineLab

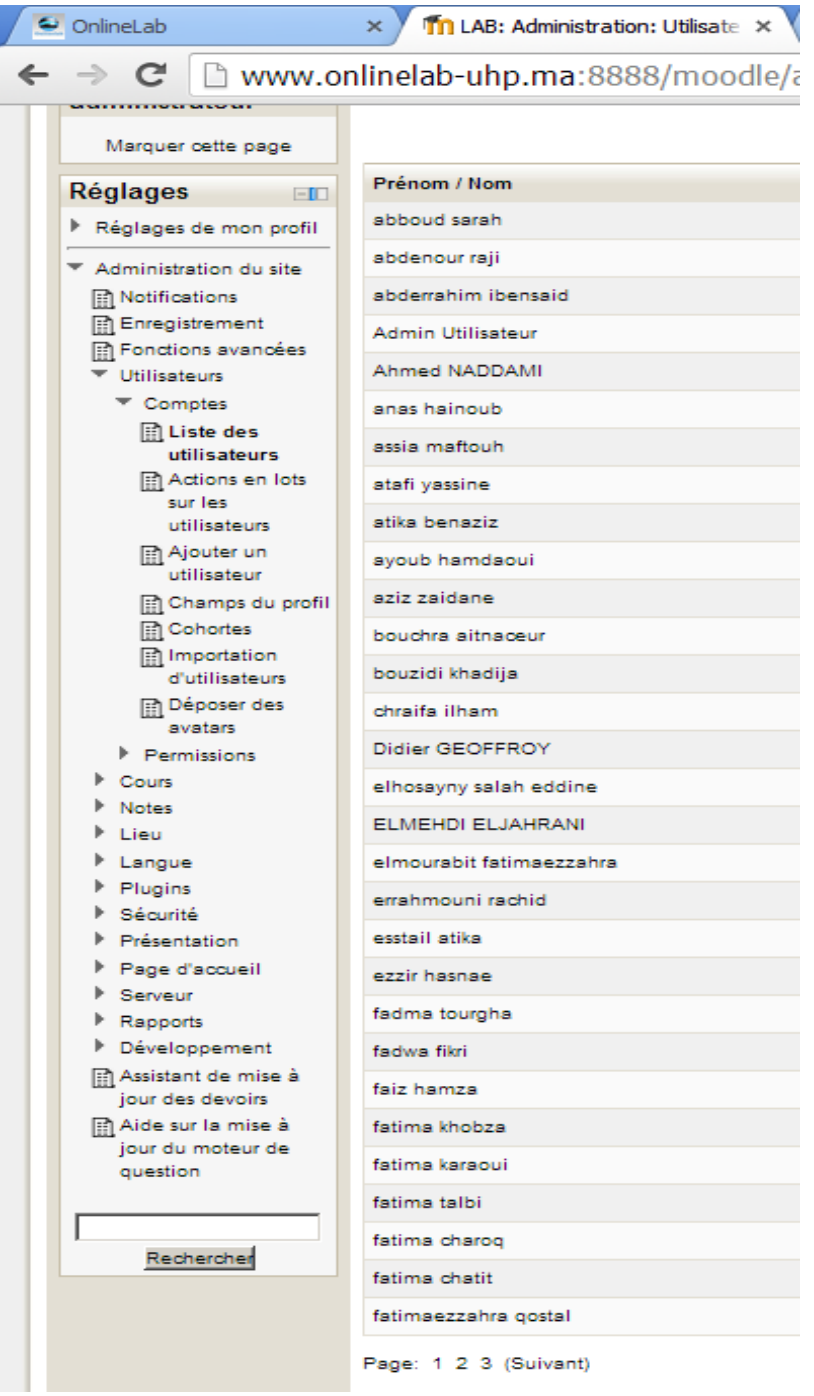

Figure 14. Students registered in Khouribga OnlineLab 


\section{REFERENCES}

[1] Kimberly DeLong, V. Judson Harward, Philip Bailey, James Hardison, Gordon Kohse, Yakov Ostrocsky "Three Online Neutron Beam Experiments Based on the iLabShared Architecture", Education Engineering (EDUCON), Madrid, pp .145 - 150,14-16 April 2010.

[2] Hardison, J., DeLong, K., Bailey, P., Harward, V.J., "Deploying Interactive Remote Labs Using the iLab Shared Architecture," Frontiers in Education (FIE) Conference, Saratoga Springs, New York, October 22-25, 2008. iLab

[3] Jiwaji, A., J. Hardison, K. P. Ayodele, S. Stevens, A, Mwanbela V. J. Harward, J. A. del Alamo, B. Harrison, and S. Gikandi, "Collaborative Development of Remote Electronics Laboratories: The ELVIS iLab." 2009 ASEE Annual Conference \& Exposition., Austin, TX, June 14-17, 2009.

[4] Harward, V.J., et al, "The iLab Shared Architecture: A Web Services Infrastructure to Build Communities of Internet Accessible Laboratories," Proceedings of the IEEE , vol.96, no.6, pp.931-950, June 2008 http://dx.doi.org/10.1109/JPROC.2008.921607

[5] Ali, F.H.; Mahmood, H.M.; Ismael, S.M.B."LabVIEW FPGA implementation of a PID controller for D.C. motor speed control.' International Conference on Energy, Power and Control (EPC-IQ), Basrah, pp.139-144, Nov. 30 2010-Dec. 22010.

[6] http://www.ni.com/

[7] Karen Butler-Purry and Hung-Ming Chou (2011). Real-Time Rapid Embedded Power System Control Prototyping Simulation Test-Bed Using LabVIEW and RTDS, Practical Applications and Solutions Using LabVIEW ${ }^{\text {TM }}$ Software, Dr. Silviu Folea (Ed.), ISBN: 978-953-307-650-8, InTech.

[8] Shroff, R., Soumare, H., Hardison, J., del Alamo, J., Harward, J., et al. (2009). "A Versatile Internet-Accessible Electronics Workbench with Troubleshooting Capabilities.” REV 2009, Bridgeport, CT, June 2009.
[9] Akinwale, O., Kehinde, L., Ayodele, K., Jubril, A., Jonah, O., et al. (2009). "A LabVIEW-based On-line Robotic Arm for Students' Laboratory.” ASEE, Austin, TX, June 14, 2009.

[10] Vesely, L, Pohl, L. "Modeling and real-time control of permanent magnet synchronous motor on cRIO,"Control, Automation and Systems (ICCAS),JeJu Island,pp.1217 - 1220,17-21 Oct. 2012

[11] Das, A.D.,Mahapatra, K.K. "Real-Time Implementation of Fast Fourier Transform (FFT) and Finding the Power Spectrum Using LabVIEW and CompactRIO",Communication Systems and Network Technologies (CSNT),Gwalior,pp. 169 - 173, 6-8 April 2013.

\section{AUTHORS}

Ahmed Naddami is with the Department of Electrical Engineering, The Polydisciplinary Faculty in Khouribga, Hassan $1^{\text {st }}$ University, Laboratoire EROM, 26000 Settat, Morocco (e-mail:ahmed.naddami@gmail.com).

Ahmed Fahli is with the Department of Electrical Engineering, The Polydisciplinary Faculty in Khouribga, Hassan $1^{\text {st }}$ University, Laboratoire EROM, 26000 Settat, Morocco (e-mail:fahli@uhp.ac.ma).

Mourad Gourmaj is with the Department of Electrical Engineering, The Polydisciplinary Faculty in Khouribga, Hassan $1^{\text {st }}$ University, Laboratoire EROM, 26000 Settat, Morocco (e-mail: mourad.gourmaj@gmail.com).

Mohammed Moussetad is with the Faculty of Sciences Ben M'Sik in Casablanca, Hassan II University Mohammedia, Laboratoire LIMAT, B.P: 7900, Casablanca, Maroc Morocco (e-mail: m.moussetad@gmail.com).

Submitted 25 November 2013. Published as re-submitted by the authors 28 April 2014. 